\title{
Obstructive Hydrocephalus Caused by an Unruptured Arteriovenous Malformation Successfully Treated by Endoscopic Third Ventriculostomy After Shunt Dysfunction
}

\author{
Charles CHAMPEAUX, Céline BOTELLA, Etienne LEFEVRE, Bertrand DEVAUX \\ Sainte-Anne Hospital, Department of Neurosurgery, Paris, France \\ 1 \\ To watch the surgical videoclip, please visit http://turkishneurosurgery.org.tr/images/19435-video.mp4
}

\section{ABSTRACT}

The authors report on a patient harbouring an unruptured cortical arteriovenous malformation (AVM), who had presented with obstructive hydrocephalus due to compression of the cerebral aqueduct by a large venous varix. A ventriculoperitoneal (VP) shunt was inserted in emergency. Due to its large volume, the AVM was not referred for treatment and a follow-up policy was chosen. After the second VP shunt dysfunction, endoscopic third ventriculostomy was performed under neuronavigation. The procedure went uneventfully and the patient recovered well. In the rare eventuality of obstructive hydrocephalous caused by an unruptured AVM, endoscopic third ventriculostomy is feasible, efficient and can avoid shunt-related complications.

KEYWORDS: Obstructive hydrocephalus, Arteriovenous malformation, Endoscopic ventriculostomy, Shunt failure

ABBREVIATIONS: AVM: Arteriovenous malformation, CSF: Cerebro-spinal fluid, ETV: Endoscopic third ventriculostomy, MRA: Magnetic resonance imaging angiography, VP: Ventriculo-peritoneal

\section{INTRODUCTION}

$\mathrm{H}$ ydrocephalus is a common medical condition caused by numerous congenital and/or acquired factors. Like most intracranial bleedings, a ruptured brain arteriovenous malformation (AVM) may generate a communicating hydrocephalus. In contrast, obstructive hydrocephalus is very rarely caused by an unruptured AVM (4).

Endoscopic third ventriculostomy (ETV) has been widely accepted as a procedure of choice for the treatment of obstructive hydrocephalus. However, in case of obstructive hydrocephalus due to a large AVM, most neurosurgeons would rather insert an internal ventricular shunt than perform an endoscopic procedure as it seems to be hazardous (4).
Through the following report, we want to bring some argument for the use of ETV in the treatment of obstructive hydrocephalus caused by unruptured AVM.

\section{CASE REPORT}

\section{Initial Presentation}

A 54-year old man presented with worsening walking disturbance, unsteadiness associated with intermittent episodes of left-sided hemiparesis, and paraesthesia of the left foot for the last 2 months. He was being treated for severe type 1 diabetes mellitus and known to have a smoking-related chronic obstructive pulmonary disease. A computed tomography (CT) scan showed a large right-sided thalamic, insular and capsular AVM with dilated ventricles (Figure 1F). The magnetic 
resonance imaging (MRI) scan confirmed the diagnosis of AVM and identified an obstructive hydrocephalus due to the obstruction of the mesencephalon's aqueduct of Sylvius by an ectatic vein (Figure $1 \mathrm{~A}-\mathrm{D}$ ). Subsequently, he underwent insertion of a ventriculo-peritoneal (VP) shunt $\left(\mathrm{Codman}^{\circledR}\right.$ Hakim $^{\circledR}$ Programmable Valve).

The cerebral angiography demonstrated a large nidus feed by numerous hypertrophic vessels from the carotid and basilar arteries with only a deep venous drainage (Spetzler-Martin Grade 5) (Figure 1E)(11). After multidisciplinary discussion, a clinical and radiological surveillance was opted for and proved to be wise as the AVM did not show any size or hemodynamic change over regular controls or bleed in 11 years. However, the shunt needed a revision 8.5 years after the implantation following its dysfunction and recurrence of the symptoms. The whole system was replaced.

\section{Second Presentation}

Two years later, he presented to the local medical emergency unit following a fall and complaining of drowsiness, abdominal pain and incontinence. C-reactive protein (CRP) was $89 \mathrm{mg} / \mathrm{L}$. The body CT scan showed a minor compression-fracture of the superior plate of L2, a subhepatic collection surrounding the distal end of the peritoneal catheter, and acute hydrocephalus. He was subsequently transferred to our department. A new shunt dysfunction was ascertained possibly associated with an infection of the valve. After discussion, it was decided to perform an endoscopic procedure and to remove all the material.
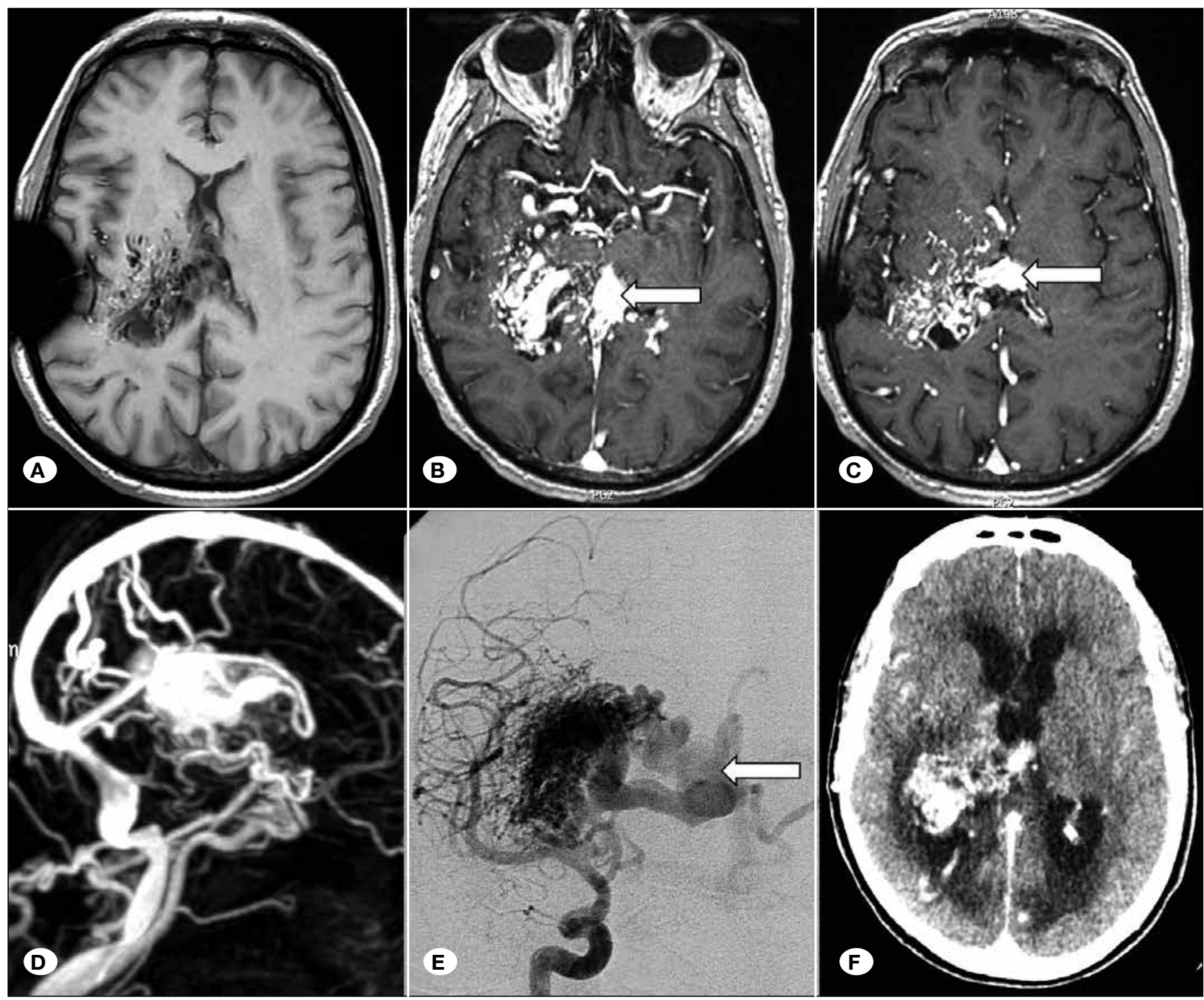

Figure 1: A) Axial T1-weighted MRI depicting the AVM. The black shadow on the left is an artefact produce by the valve. B and C) Axial 3D fast spoiled gradient echo (FSPGR) showing the AVM and the dilated vein obstructing the aqueduct (white arrow). D) Timeresolved imaging of contrast kinetics (TRICKS) MRA. E) Angiography in frontal view showing the AVM and the dilated vein obstructing the aqueduct (white arrow). F) lodine-contrast enhanced CT scan showing non-communicating hydrocephalus following VP shunt dysfunction. 


\section{Surgical Procedure}

Under general anaesthesia, the patient's head was fixed in the three-pin Mayfield ${ }^{\circledR}$ head clamp and the scalp prepared according the current protocol of asepsis. Neuronavigation (Brainlab ${ }^{\circledR}$ curve $^{\mathrm{TM}}$ 110) was used to select a left-sided entry point, behind the coronal suture. A draining vein was narrowing the right foramen of Monroe. Therefore, we selected a safer straight path from the cortex to the floor of the third ventricle, via the foramen of Monroe (Figure 2A-C).

The Lotta ${ }^{\circledR}$ system $6^{\circ}$ for intracranial neuroendoscopy with an operating sheath $6.8 \mathrm{~mm}$ in diameter (Karl Storz $\mathrm{GmbH}$ \& Co. KG) was used to perform the surgery. Once in the third ventricle, the floor was punctured with the blunt coagulator without coagulating and the stoma was enlarged with a NeuroBalloon ${ }^{\mathrm{TM}}$ Catheter (Integra LifeSciences Corporation ${ }^{\circledR}$ ).

The endoscope was gently pulled out (Video). A bleeding vein of the foramen of Monroe was coagulated. The column of the fornix was slightly contused. The left lateral ventricle was washed until the cerebrospinal fluid (CSF) became clear and the system removed. A standard closure was achieved. The right VP shunt was entirely extracted and sent for microbiology analysis. $20 \mathrm{~mL}$ of CSF was removed through a lumbar puncture to initiate the flow through the ventriculostomy and also sent for microbiological analysis.

\section{Outcome}

The postoperative course was uneventful and he was discharged 7 days after the procedure. The ventricular catheter culture grew some colonies of Staphylococcus warneri, but the shunt was not proven to be infected. He was treated 14 days orally by amoxicillin with clavulanic acid. A postoperative $\mathrm{MRI}$ at the $3^{\text {rd }}$ month confirmed the CSF flow through the stoma and the ventricle's size reduction along with the disappearance of the transependymal edema. Clinically, he remains well 8 months after the procedure.

\section{DISCUSSION}

VP shunt insertion is the most common procedure for hydrocephalus treatment. However, it is impeded by frequent complications and malfunctions with reported longterm shunt revisions around $80 \%$ (2). ETV is a quite recent alternative to shunt implantation, mainly used in obstructive hydrocephalus with an overall success rates about $75 \%$ and a low complication rate, below $5 \%$.

Overdrainage is another drawback of shunts that may cause symptoms following subdural hematoma, hygroma and slit ventricles. Such complications can be avoided with ETV, because it would not change the balance between the supratentorial and infratentorial pressures.

Endoscopic surgery is generally considered advantageous to treat obstructive hydrocephalus due to compression of the Sylvius aqueduct by a tumor or aqueductal stenosis. Advances in optical technology and greater confidence in endoscope handling have allowed new indications e.g. in colloid and arachnoid cysts.

Overall morbidity rates of ETV are usually from 3.6 to $10 \%$, although most complications are minor (CSF leak, infection, haemorrhage) $(2,10)$. Complications and failure rates increase with younger age. The use of ETV has reduced the number of shunt insertions and related hospital admissions for failures, which has been a source of cost savings $(10,12)$.

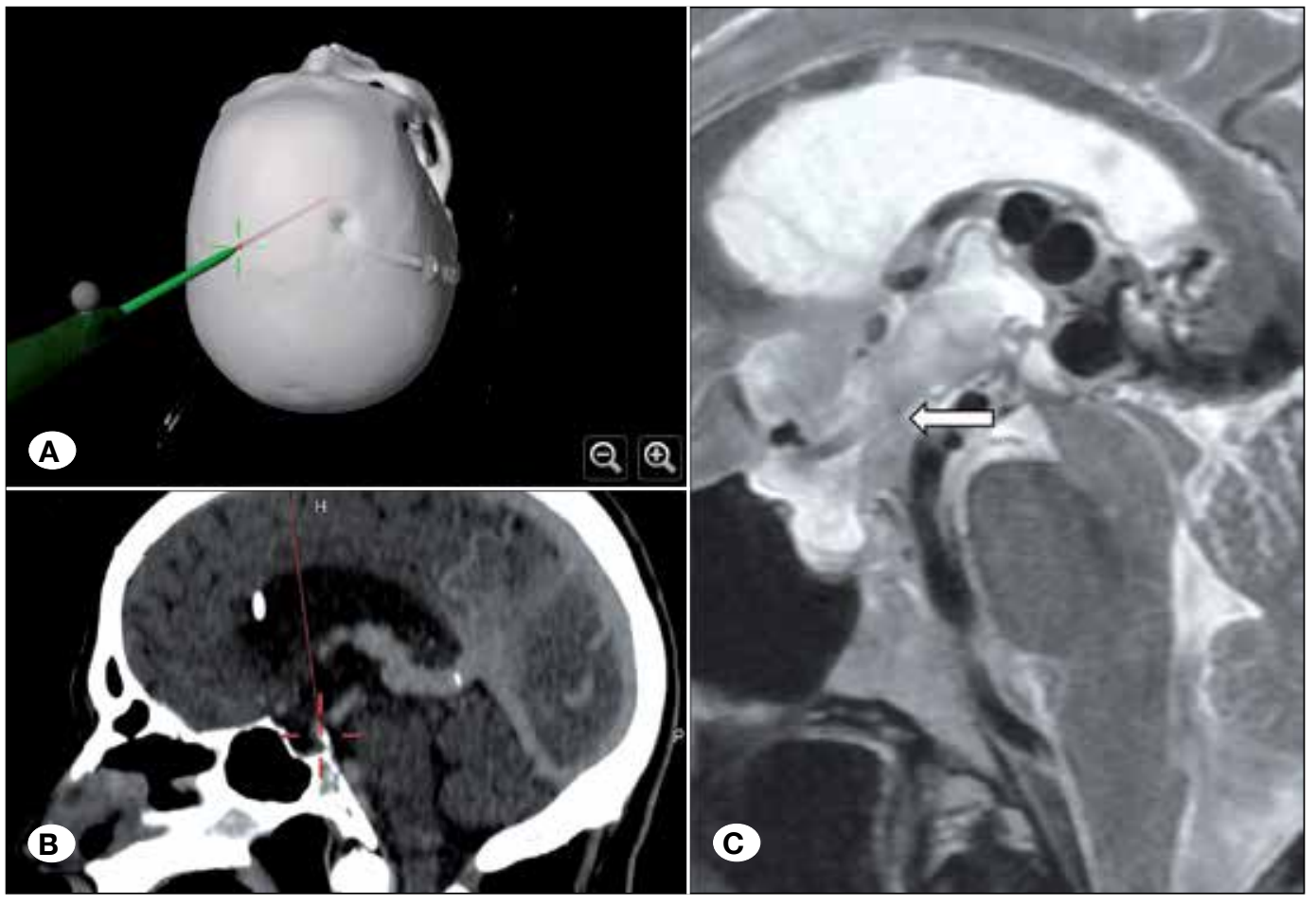

\section{Figure 2:}

A and B) Brainlab ${ }^{\circledR}$ neuronavigation surgical planning.

C) 4-month postoperative sagittal T2 MRI showing the artefact of the CSF flow through the ventriculostomy. 
Table I: Literature Review of Hydrocephalus due to Unruptured AVM Treated by Neuroendoscopy

\begin{tabular}{|c|c|c|c|c|c|c|c|}
\hline $\begin{array}{l}\text { Authors } \\
\text { (year) }\end{array}$ & Gender & $\begin{array}{c}\text { Age at } \\
\text { presentation }\end{array}$ & $\begin{array}{l}\text { Localisation } \\
\text { of the AVM }\end{array}$ & $\begin{array}{l}\text { Spetzler- } \\
\text { Martin } \\
\text { grade }\end{array}$ & Cause of hydrocephalus & $\begin{array}{l}\text { Outcome } \\
\text { (GOS) }\end{array}$ & Remark \\
\hline Present case & M & 54 years & $\begin{array}{l}\text { Thalamic insular } \\
\text { \& capsular }\end{array}$ & V & $\begin{array}{c}\text { Dilated vein blocking the } \\
\text { aqueduct }\end{array}$ & 5 & $\begin{array}{l}\text { Previously shunted } \\
2 \text { shunts failures }\end{array}$ \\
\hline $\begin{array}{l}\text { Ono } 2015 \\
\text { (6) }\end{array}$ & M & 56 years & Cerebellar vermis & IV & $\begin{array}{c}\text { Aqueduct compressed by a } \\
\text { dilated precentral cerebellar } \\
\text { vein }\end{array}$ & 5 & $\begin{array}{c}\text { Partial embolization } \\
\text { before the ETV }\end{array}$ \\
\hline $\begin{array}{l}\text { Rodriguez } \\
2013 \text { (9) }\end{array}$ & M & 83 years & Posterior fossa & V & $\begin{array}{c}\text { Dilated vein of Galen } \\
\text { compressing the aqueduct } \\
\text { of Sylvius }\end{array}$ & 5 & None \\
\hline $\begin{array}{l}\text { Rodriguez } \\
2013 \text { (9) }\end{array}$ & $\mathrm{F}$ & 64 years & Posterior fossa & IV & $\begin{array}{c}\text { Dilated vein of Galen } \\
\text { compressing the aqueduct } \\
\text { of Sylvius }\end{array}$ & 5 & None \\
\hline $\begin{array}{l}\text { Rezaee } 2007 \\
(8)\end{array}$ & $\mathrm{NA}^{1}$ & NA & NA & NA & NA & 5 & Calcified AVM \\
\hline $\begin{array}{l}\text { Pereira } 2002 \\
\text { (7) }\end{array}$ & $\mathrm{M}$ & 41.8 years & Pineal region & NA & $\begin{array}{l}\text { Dilated \& calcified vein of } \\
\text { the pineal region }\end{array}$ & 5 & $\begin{array}{l}\text { Embolization after } \\
\text { the ETV }\end{array}$ \\
\hline
\end{tabular}

${ }^{1}$ NA: Not Available, M: Male, F: Female, GOS: Glasgow Outcome Score.

The common presentation of intracerebral AVM is haemorrhage. Rarely hydrocephalus leads to an AVM discovery as we found only 18 cases of hydrocephalus caused by an unruptured AVM in the literature (4,6-9). In the present case, the cerebral angiography showed a very large AVM, supply by numerous perforant arteries with an exclusive deep venous drainage (Spetzler-Martin Grade 5) (11). Endovascular embolization or stereotactic radiotherapy was not considered as achievable to treat the AVM satisfactorily and safely. Moreover, the patient symptoms were related to the hydrocephalus, and not the AVM. While intervention for ruptured brain AVMs is typically warranted, management of unruptured AVMs remains controversial. Only one randomized controlled trial has been conducted (ARUBA). To great controversy, the study concluded that medical management alone was superior to intervention for unruptured AVMs $(3,5)$.

Varices of the deep venous system occluding the foramen of Monro or the aqueduct of Sylvius were generally the cause of the obstruction. Usual treatment for obstructive hydrocephalus due to an AVM is VP shunting. In 2013, Rodriguez and Teixido wrongly wrote that they were the first to report the endoscopic treatment of hydrocephalus caused by an AVM. Their neighbour country was, in fact, the first to publish in 2002 a successful ETV for hydrocephalus due to a pineal AVM (7). We searched MEDLINE (1946 to November 2016) with no language restrictions and identified 5 cases that are summarized in the Table I (6-9). No surgical complication was reported. In the present case, following the recurrent VP shunt dysfunction with the suspicion of infection, we decided to perform an alternative hydrocephalus treatment. Achievement of the ETV in this condition was no more complicated than in usual ETV cases, but feeling a bit more hazardous. Neuronavigation was helpful to search for the best entry point and to avoid dilated vessels.

For neurosurgeons trained in neuroendoscopy, this unusual cause of obstructive hydrocephalus should not be a contraindication to perform an ETV. The opportunity for patients with blocked hydrocephalus to be "shunt free" after an ETV should be discussed and considered as a major advantage. Chhun et al. confirmed that ETV should be the first therapeutic option to pursue before shunt revision in cases of initial obstructive hydrocephalus, with a success rate of $70 \%$ similar to primary procedures (1). Present and reported cases were all doing-well and shunt free at 8 months.

\section{CONCLUSION}

In the rare eventuality of obstructive hydrocephalous caused by an unruptured AVM, endoscopic third ventriculostomy is feasible, efficacious and can avoid shunt-related complications.

\section{ACKNOWLEDGMENT}

The authors thank the following people for their assistance: Jun Muto 武藤 淳 for the Japanese translation and Maria Da Silva for the Portuguese translation.

\section{REFERENCES}

1. Chhun V, Sacko O, Boetto S, Roux FE: Third ventriculocisternostomy for shunt failure. World Neurosurg 83: 970-975, 2015

2. Grand W, Leonardo J, Chamczuk AJ, Korus AJ: Endoscopic third ventriculostomy in 250 adults with hydrocephalus: Patient selection, outcomes, and complications. Neurosurgery 78: 109-119, 2016 
3. Hong CS, Peterson EC, Ding D, Sur S, Hasan D, Dumont AS, Chalouhi N, Jabbour P, Starke RM: Intervention for a randomized trial of unruptured brain arteriovenous malformations (ARUBA) - Eligible patients: An evidencebased review. Clin Neurol Neurosurg 150:133-138, 2016

4. Mindea SA, Yang BP, Batjer H: Unruptured arteriovenous malformation in a patient presenting with obstructive hydrocephalus. Case report and review of the literature. Neurosurg Focus 22: E11, 2007

5. Mohr JP, Parides MK, Stapf C, Moquete E, Moy CS, Overbey JR, Al-Shahi Salman R, Vicaut E, Young WL, Houdart E, Cordonnier C, Stefani MA, Hartmann A, von Kummer R, Biondi A, Berkefeld J, Klijn CJ, Harkness K, Libman R, Barreau X, Moskowitz AJ; international ARUBA investigators: Medical management with or without interventional therapy for unruptured brain arteriovenous malformations (ARUBA): A multicentre, non-blinded, randomised trial. Lancet 383:614621, 2014

6. Ono K, Oishi H, Suga Y, Yamamoto M, Nonaka S, Nakajima $\mathrm{M}$, Miyajima $\mathrm{M}$, Arai $\mathrm{H}$ : Case report of cerebellar vermis arteriovenous malformation presenting with hydrocephalus due to aqueductal stenosis. No Shinkei Geka 43: 843-848, 2015 (In Japanese)
7. Pereira J, Lamas R, Ayres-Basto M, Seixas ML, Vaz R: Neuroendoscopy in the treatment of obstructive hydrocephaly. Acta Méd Portu 15: 355-364, 2002 (In Portuguese)

8. Rezaee O, Sharifi G, Samadian M, Haddadian K, Ali-Asgari A, Yazdani M: Endoscopic third ventriculostomy for treatment of obstructive hydrocephalus. Arch Iran Med 10: 498-503, 2007

9. Rodríguez Rodríguez R, Molet Teixido J: Letter to the Editor of Acta Neurochirurgica: Obstructive hydrocephalus caused by unruptured arteriovenous malformation treated with endoscopic third ventriculostomy. Acta Neurochir 155: 901902, 2013

10. Sacko O, Boetto S, Lauwers-Cances V, Dupuy M, Roux FE: Endoscopic third ventriculostomy: Outcome analysis in 368 procedures. J Neurosurg Pediatr 5:68-74, 2010

11. Spetzler RF, Martin NA: A proposed grading system for arteriovenous malformations. J Neurosurg 65: 476-483, 1986

12. Xu R, McCrea HJ, Hoffman CE, Souweidane MM, Greenfield JP: The impact of endoscopic third ventriculostomy on shunt revision rate: $A$ 14-Year experience at a single institution. World Neurosurg 84: 677-680, 2015 